\title{
La Colonia del Doctor Rubio: la utopía de los higienistas en el Alto Guadarrama
}

\section{Doctor Rubio's Colony: the utopia of the higienists in the Guadarrama}

\author{
Miguel Ángel Soto CaBA \\ Investigador \\ nanquisoto@gmail.com
}

Recibido: 30/04/2015

Aceptado: 21/09/2015

\section{Resumen}

La Colonia del Doctor Rubio, construida en los primeros años del siglo XX en las proximidades del manantial de aguas minero-medicinales de La Porqueriza (Guadarrama, Madrid), contaba con un hotel, un casino con teatro, capilla, hotelitos o villas, y toda una infraestructura de servicios. La colonia toma el nombre del Doctor Federico Rubio y Galí, figura fundamental de la medicina en el siglo XIX ligada a los ambientes intelectuales madrileños y los movimientos Higienista y de la Institución Libre de Enseñanza. La apuesta urbanística es contemporánea de la Ciudad Lineal de Arturo Soria, e imita los modos y modas del balnearismo propio de la Belle Èpoque, pero también es expresión de los cambios en la lucha antituberculosa, anticipando el modelo de cura sanatorial en zonas de montaña implantado en el último tercio del siglo XIX en otros países europeos y EE.UU. En este trabajo se expone los orígenes del proyecto, los códigos culturales y el lenguaje arquitectónico de lo que hemos definido como la "utopía de los higienistas" en el Guadarrama. 


\title{
Palabras clave
}

Balnearismo, sanatorio tuberculoso, Ciudad Lineal, Federico Rubio y Galí, Sierra de Guadarrama.

\begin{abstract}
Doctor Rubio's Colony, built in the early years of the twentieth century near the source of the medicinal waters of The Porqueriza (Guadarrama, Madrid), consisted of a hotel, a casino with theatre, chapel, cottages or villas, and a whole service infrastructure. The colony use the name of Dr. Federico Rubio y Galí, an important figure in medicine in this period, linked with intelectual movement of Higienismo and Institución Libre de Enseñanza. This project was contemporary with the development of Ciudad Lineal, designed by Arturo Soria, and mimics the ways and fashions of the Belle Époque in the spas of this period. It is also an expression of changes in tuberculosis treatment, replicating the model sanatorium cure instituted for decades in mountain areas in european countries and USA. In this paper we have investigated the origins of the project, the ideas and influences and the architectural language of this "health utopia."
\end{abstract}

\section{Keywords}

Spa, tuberculosis sanatorium, Ciudad Lineal, Federico Rubio y Galí, Guadarrama Range.

Referencia normalizada: SOTO CABA, Miguel Ángel (2015): “La Colonia el Doctor Rubio: la utopía de los higienistas en el Alto Guadarrama". Arte y Ciudad. Revista de Investigación, no 8 (octubre), págs. 83-114. Madrid. Grupo de Investigación Arte, Arquitectura y Comunicación en la Ciudad Contemporánea, Universidad Complutense de Madrid.

Sumario: 1.- Introducción. 2.- La lucha contra la tuberculosis: entre la hidrología médica y la bacteriología. 3.- El prestigio de Federico Rubio y Galí como aval del proyecto. 4.Gestación, auge y decadencia de la Colonia del Doctor Rubio. 5.- La Colonia del Doctor Rubio y las utopías del siglo XIX. 5.1.- Hygeia, la ciudad higiénica, la "ciudad ideal". 5.2.- La Ciudad Lineal de Arturo Soria. 5.3.- La ciudad balnearia, entre la salud y el veraneo. 5.4.- Los sanatorios antituberculosos. 6.- Conclusiones. La unión de los contrarios y la ciudad. 7.- Bibliografía y Hemeroteca. 


\section{Introducción}

La Colonia del Doctor Rubio se construye en la localidad de Guadarrama (Madrid) entre 1901 y 1904. Su gestación es contemporánea a las nuevas funciones sociales otorgadas a la Sierra de Guadarrama y a la expansión entre las clases acomodadas madrileñas del concepto del ocio al aire libre y el veraneo. Este fenómeno será el detonante de la posterior ocupación y transformación física de este territorio, a través de la construcción de villas, residencias y colonias veraniegas.

Este primer acercamiento de la urbe madrileña al Guadarrama se ha hecho posible gracias a la construcción del Ferrocarril del Norte, que a partir de 1861 conecta la capital con El Escorial, pasando por Villalba. En el caso que nos ocupa, además, la localidad de Guadarrama suma a la muy buena accesibilidad desde la Estación de Villalba la existencia de un manantial de aguas mineromedicinales, La Porqueriza, que añade al emplazamiento un atractivo suficiente para movilizar iniciativas económicas que intentarán hacer de esta localidad un centro de salud y ocio capaz de competir con las ciudades balnearias que se han puesto de moda en el último tercio del siglo XIX.

El auge de la Hidrología Médica y el Balnearismo harán posible que los atractivos del agua, el aire y el paisaje del Guadarrama se presenten como la solución al problema sanitario de Madrid, ciudad insalubre que en el cambio de siglo ha vivido varias epidemias de viruela y gripe y sufre una alta tasa de mortalidad por tuberculosis. Por su buena accesibilidad, por la fama de sus aguas y por albergar las primeras experiencias del tratamiento de la tuberculosis mediante la cura sanatorial en altura, la localidad madrileña de Guadarrama se significará durante el resto del siglo XX en el mapa nacional de la lucha antituberculosa con la construcción de sanatorios y preventorios infantiles.

Contemporánea de la Colonia del Doctor Rubio, el Hotel-Balneario de la Alameda y sus aguas medicinales recomendadas para enfermos del estómago, aumentará la oferta sanitario-recreativa de Guadarrama y convertirá a esta localidad en el lugar elegido por una parte de las élites madrileñas para imitar los hábitos y gustos propios de la Belle Époque, reproduciendo a escasa hora y media de Madrid estampas propias de centros balnearios de mayor renombre. Ambos establecimientos, junto con el Hostal Castilla o la incipiente colonia de hotelitos construidos en esta localidad, serán el punto de partida para que ve- 
raneantes, excursionistas y enfermos adopten modos de vida refinados, acudan a tomar las aguas ("agüistas" los llamará la prensa) y disfruten del aire y el paisaje del Guadarrama.

Este trabajo profundiza sobre los orígenes de esta colonia sanatorial y reflexiona sobre la figura del Doctor Federico Rubio y Galí, médico que dará nombre al proyecto. La aproximación al lenguaje urbanístico y arquitectónico ha sido posible a través de fotos y postales de la colonia y del sanatorio en sus diversas épocas, tanto de archivos públicos como privados. El mapa de la Colonia se ha establecido a partir de un mapa-croquis de 1917, la fotografía aérea del vuelo de 1956 y la localización de las fotografías de los principales edificios en dicho mapa. A través de las crónicas de la prensa madrileña ha sido posible también conocer los hábitos sociales y la liturgia de "tomar las aguas" propias del balnearismo de este tiempo.

Por último, hemos querido comparar este modelo residencial con las utopías higienistas y las propuestas urbanísticas propias de finales del siglo XIX, estableciendo similitudes con otros proyectos de este mismo periodo, como la Ciudad Lineal de Arturo Soria, las ciudades balnearias o los sanatorios antituberculosos que se han generalizado en Europa a finales del siglo XIX.

\section{La lucha contra la tuberculosis: entre la hidrología médica y la bacteriología.}

Para entender el origen de este proyecto hemos considerado necesario aproximarnos al problema de la tuberculosis y su relación con la vivienda y el estado sanitario de Madrid.

La tuberculosis es el prototipo de enfermedad social infecciosa crónica. Su microorganismo responsable, el Mycobacterium tuberculosis, provoca la reacción inflamatoria de los tejidos orgánicos afectados, siendo los pulmones su lesión más extendida, seguidos del intestino, los ganglios linfáticos (escrófulas), la piel (lupus tuberculoso), los órganos génito-urinarios y los huesos (osteo-artritis tuberculosa, espondilitis o mal de Pott, etc.) (Báguena Cervellera, 1992).

Durante el siglo XIX, la industrialización y la emigración masiva a las ciudades provocaron una expansión sin precedentes de la tuberculosis, haciendo de ella una enfermedad social (Ruiloba, 2011). Y es precisamente en el último tercio del siglo XIX cuando cristaliza la preocupación de los higienistas españo- 
les por las viviendas insalubres, por las condiciones de humedad, falta de luz y ventilación y, sobre todo, hacinamiento, derivado de la mala distribución de los espacios en el interior de las viviendas. La consecuencia inmediata de tal hacinamiento es la escasez del aire respirable en dichos espacios y, entre las enfermedades de la época, será la tuberculosis en donde estará más y mejor documentada su relación con el hacinamiento, hasta el punto de recibir el apelativo de "enfermedad de las viviendas" (Huertas, 2002).

En el Congreso de Higiene de 1882, la mala salud de los madrileños se achacará a aspectos de higiene pública general: el clima de Madrid, la densidad de población, la excesiva altura de los edificios, las malas condiciones de las alcantarillas, la permeabilidad excesiva del suelo y las deficientes condiciones higiénicas de los mercados y hospitales (Huertas, 2002). En estas últimas décadas del siglo XIX, Madrid sufre diversas epidemias: viruela en 1889 y 1890, año este último al que se sumó una epidemia de gripe. Aquel mismo año, 1890, Madrid era "la ciudad triste", "que no ríe", "sin aire, sin agua, sin luz" (El Imparcial, 3/11/1890).

Desde la antigüedad, los escritos Hipocráticos (siglos V y IV a.C.) habían recomendado reposo, baños y dieta líquida en casos agudos de tuberculosis; la medicina helenística recomendó largos viajes por mar y un cambio a un clima más seco, junto a buena dieta y reposo; y Galeno en el siglo II recomendaba también el reposo y una dieta que detalló minuciosamente, así como los emplastos aplicados al pecho (Báguena Cervellera, 1992). La utilización del arsénico para paliar, entre otras enfermedades, la tuberculosis, había sido defendida por Galeno y pervivirá todavía durante algunos años del siglo XX. Pero no será hasta 1943, con el aislamiento del primer antibiótico contra el bacilo, la estreptomicina, cuando se consiga un tratamiento eficaz contra esta enfermedad.

La polémica sobre su carácter hereditario o contagioso, debatida ampliamente durante la segunda mitad del siglo XIX, continuará incluso con posterioridad a 1882, cuando Robert Koch aisla el bacilo causante de la tuberculosis.

Ese mismo año, 1882, la Sociedad Española de Hidrología Médica debate de manera errática el origen y desarrollo de esta enfermedad, recomendando la aplicación terapéutica de las aguas azoadas (nitrogenadas), clorurado-sódicas y arsenicales para combatir la tuberculosis. Los hidrólogos médicos defendían que esta enfermedad 
no es debida a la especificidad de un virus ni la implantación y vida en los tejidos o humores de seres parasitarios, sino que es una degradación universal del organismo (...) entre las cuales (causas) juega el principal papel una predisposición orgánica definida (Manzaneque, 1882).

En 1888, tras un congreso sobre esta enfermedad celebrado en París, los médicos españoles debatirán en el Congreso de Ciencias Médicas no ya la existencia por entonces probada del bacilo de Koch, sino su grado de contagiosidad (Báguena Cervellera, 1992).

Aunque la Hidrología Médica recomendaba el tratamiento de la tuberculosis mediante aguas arsenicales personalizando caso a caso, advertían que las aguas arsenicales tenían una acción principalmente preventiva, siendo más eficaz en los primeros estadios de la enfermedad. Por eso, las indicaciones principales de las aguas minero-medicinales eran el tratamiento de "los estados de decadencia orgánica” previos a la tuberculosis (Martínez Galán, 1997).

Algunos años antes de la fundación de la Colonia del Doctor Rubio, las aguas arsenicales, ferruginosas y radioactivas de los manantiales del piedemonte del Guadarrama fueron expedidas en las farmacias de Madrid para combatir la tuberculosis. Es el caso de las aguas de Moralzarzal, localidad que cuenta con una Fuente de la Salud documentada al menos desde el siglo XVII y donde las aguas de los manantiales La Fe y La Fe Perseverante fueron embotelladas y comercializadas en Madrid durante el periodo 1877-1890 (López \& Soto, 2013). Esta localidad, situada a algunos kilómetros de Guadarrama, llegó a acoger 125 "enfermos" en el periodo 1886-1889, según el Resumen Estadístico Oficial de la Aguas Minerales en España (Taboada y Carretero, 1890). La tradición sanatorial de Moralzarzal perdurará en el siglo XX, y el establecimiento minero-medicinal de La Fe del Portillo de La Mina intentará sumarse, sin lograrlo, a la moda balnearia que se instaura en la localidad vecina de Guadarrama (López \& Soto, 2013). La composición química de las aguas poco debía de importar: la generalización de un tratamiento basado en la combinación de reposo, buena alimentación y aguas medicinales provocaba que incluso el balneario de El Molar, de aguas cloruro-sódico-sulfatadas-sulfrídicas, se recomendara para enfermos de escrófulas, herpetismo y catarros (El Imparcial, 9/5/1899).

A diferencia de estas aguas de mayor tradición medicinal, la localidad de Guadarrama contaba con mayor altitud, un paisaje serrano y buenas comuni- 
caciones. Con estas ventajas estratégicas, y en un momento de transición entre los postulados de la hidrología médica y la irrupción del nuevo paradigma de la bacteriología, la Colonia del Doctor Rubio combinará, cual balneario, la práctica del veraneo con el combate de la tuberculosis a través del tratamiento con aguas arsenicales y nitrogenadas, para abandonarlo progresivamente por la cura sanatorial de reposo en altura, la exposición al sol y una dieta hípercalórica.

La aceptación general del carácter infeccioso de la enfermedad, el conocimiento generalizado del descubrimiento de Koch, los primeros ensayos de una vacuna (la tuberculina) y, en definitiva, la implantación del paradigma bacteriológico, tardarán todavía en extenderse por los hospitales y sanatorios más avanzados de Europa. En el caso de España, además, los adelantos médicos llegarán con algunos años más de retraso (Báguena Cervellera, 1992).

En los primeros años del siglo, se conoce ya el riesgo de contagio y la inconveniencia de mezclar enfermos con personas sanas. Los Anales de la Real Academia de Medicina de Madrid recogen en sus Actas de Sesiones Literarias la visita el 20 de junio de 1903 de los doctores Bernheim y A. Roblot, de París, para dar lectura a su trabajo La lucha antituberculosa en y por la Escuela. En dicha presentación, los médicos daban noticia de un decreto novedoso del Ministerio de Instrucción Pública de Francia, donde se establecía: “Evitar los riesgos de contagio, no solamente con la observancia rigurosa de las reglas de salubridad doméstica e higiene individual, sino también con el alejamiento de los enfermos afectados de infecciones contagiosas de tuberculosis". Pero la gestación y construcción de la Colonia del Doctor Rubio se realizará todavía bajo los viejos postulados.

Ese mismo año, 1903, escasos dos años después de inagurarse la Colonia del Doctor Rubio, se funda en Madrid la Asociación Antituberculosa Española, comenzando la lucha contra esta enfermedad de forma organizada en nuestro país, germen de las futuras Juntas o Ligas provinciales y locales contra la tuberculosis, creadas en 1904. En 1906, se crea para coordinar esta asociación la Comisión Permanente de Lucha contra la Tuberculosis; en 1907, el Real Patronato Central de Dispensarios y Instituciones Antituberculosas; y en 1914 una Real Orden establece una nueva organización de la lucha antituberculosa. Esta compleja organización desaparece en 1924 para agruparse en el Real Patronato de la Lucha Antituberculosa (Báguena Cervellera, 1992). 


\section{El prestigio de Federico Rubio y Galí como aval del proyecto.}

Si el problema de la tuberculosis y su relación con la la vivienda ayudan a entender el origen de este proyecto sanatorial, la figura de Federico Rubio y Galí clarifica el ideario de sus promotores y de los movimientos sociales del momento. Federico Rubio y Gali, de quién Laín Entralgo diría que fue "tal vez el médico más importante de todo el siglo XIX" (Laín Entralgo, 1977) era, incluso antes de morir, un mito. "Pocos hombres han sentido la honda emoción de verse glorificados en vida", escribirá el Ginecólogo Eugenio Gutierrez, amigo de Rubio y primer biógrafo (Gutierrez, 1903).

Federico Rubio y Galí nació en El Puerto de Santa María (Cádiz) el 30 de agosto de 1827 y falleció en Madrid el 31 de agosto de 1902, un año después de la inauguración de la colonia que llevará su nombre.

Rubio fue un alumno brillante, licenciándose en Medicina en 1850, y ocupando pronto la plaza de primer cirujano del Hospital de Sevilla. Su padre sirvió voluntariamente en las tropas de Riego, y fue hecho prisionero y desterrado a Francia (Gutierrez, 1903). Durante su formación se relacionó con los ambientes intelectuales y políticos más progresistas, especialmente con Federico de Castro Fernández, discípulo del krausista Julián Sanz del Río. Se adhirió al republicanismo federal de Francisco Pi y Margall a partir de la revolución de 1854 pero las medidas represivas de los gobiernos derechistas le obligaron a ausentarse de España en 1860 y 1864, exilio que aprovechó para completar su formación científica en Londres y Paris. En enero de 1869 fue elegido como cabeza de la candidatura republicana para representar a Sevilla en las Cortes constituyentes, siendo elegido diputado en 1871 y, al año siguiente, senador. La I República lo nombró en 1873 embajador en Londres pero, como el Gobierno británico no llegó a reconocer al nuevo régimen español, volvió a aprovechar su estancia allí para aumentar su bagaje científico. Ese mismo año realizó un viaje a los Estados Unidos, donde visitó las principales instituciones relacionadas con la cirugía de Nueva York, Filadelfia y Chicago. En 1880 funda el Instituto de Terapéutica Operatoria en el Hospital de la Princesa en Madrid, con el objeto de impulsar la enseñanza de las especialidades quirúrgicas. Su gran creación fue el Instituto Rubio, posteriormente Instituto de La Moncloa. En su seno, en 1895 funda la Escuela de Enfermeras de Santa Isabel de Hungría, la primera escuela para enfermeras laicas en España, y que inició la moderna en- 
fermería en España. Y en 1896, el Instituto de Técnica Quirúrgica y Operatoria (Herrera, 2002).

Desde 1873 fija su residencia en Madrid, dejando la política activa a partir de 1875. Pero continuó, sin embargo, relacionado con los ambientes intelectuales más abiertos, en especial con el que rodeaba a Francisco Giner de los Ríos, participando en la fundación de la Institución Libre de Enseñanza en 1876. Rubio se confesará entusiasta de esta Institución y fiel lector de su boletín, bandera de los últimos adelantos pedagógicos (Gómez, 2003), algo que refleja la primera frase de su libro póstumo Mis Maestros y mi educación con la siguiente frase: "Hace tiempo que me preocupa el problema de la Educación. Acreció mi interés con la lectura del Boletín de la Institución Libre de Enseñanza (...)" (Rubio, 1977). Laín Entralgo, al analizar la vinculación y admiración que profesó Rubio por Giner de los Ríos y la Institución Libre de Enseñanza, traza un paralelismo entre esta institución y los diversos institutos que fundó el médico:

La estimación de Rubio por la Institución Libre de Enseñanza fue grande (...). Tan distintas entre sí por el contenido de sus enseñanzas, ¿será lícito afirmar que la Institución de Giner y el Instituto Rubio -al fondo ambas, una sociedad menestorosa de reformas educativas- fueron realidades paralelas? (Laín Entralgo, 1977).

Rubio participa también en la constitución de sociedades científicas, como la de Geografía de Madrid, en 1876, y El Folklore Castellano, creada en 1883 por el padre de los hermanos Machado, Antonio Machado y Álvarez, al que Rubio conoce de su etapa sevillana en los años 50. Rubio preside la comisión de medicina de esta última sociedad (Perdiguero y Ballester, 2003). También es miembro de la Sociedad Española de la Higiene, fundada en 1882, donde destaca uno de sus fundadores, el arquitecto Manuel Belmás (1850-1916), que sería también su primer secretario a la vez que presidente de la Sociedad Central de Arquitectos entre 1875 y 1882, y el representante español en los Congresos Internacionales de Higiene de París (1885) y Londres (1891). Belmás se inscribe dentro la línea reformista de la Institución Libre de Enseñanza y del krausismo español (Barreiros, 1992) y colabora con Arturo Soria en la construcción de la Ciudad Lineal siendo el diseñador de diversos proyectos y modelos de viviendas.

En 1889, Federico Rubio forma parte del primer intento de formar en España una Asociación contra la tuberculosis, capitaneada por el Doctor Espina y Ca- 
pó, quien había asistido el año anterior al Congreso sobre la tuberculosis celebrado en París (Báguena Cervellera, 1992). Con ellos estarán algunos médicos de primera fila: Amalio Gimeno, Ángel Pulido o José de Letamendi.

Pese a su ideario progresista y republicano, Rubio mantiene excelentes relaciones con la Corte y el poder económico y político. Su prestigio personal es su mejor aval y es solicitado por la Reina Cristina como médico personal, cargo que Rubio no acepta aunque se compromete a visitar el Palacio siempre que se le requiera (Alvarez Sierra, 1947). Atiende a la Reina Isabel en su lecho de muerte (Herrera, 2002) y ha operado al cartagenero Isaac Peral en 1895 (Marset, 2003). Como señala uno de sus biógrafos, “hubo un periodo, allá por los años 1875 a 1898, en que no podía morirse ninguna persona adinerada, ninguna persona de relieve social, sin que diese el visto bueno en Junta de Médicos D. Federico Rubio" (Alvarez Sierra, 1947).

Rubio se relaciona con la aristocracia conservadora madrileña y entabla estrecha amistad con miembros del Partido Conservador, como el Marqués del Pazo de la Merced, diputado por Vigo, Ministro de Estado durante el reinado de Alfonso XII y presidente del Senado entre 1896 y 1898. Es médico personal y amigo de Miguel López de Carrizosa y de Giles, segundo marqués de Mochales, diputado a Cortes por Jerez de la Frontera y senador vitalicio, que desempeñó el cargo de director General de Correos y Propiedades del Estado, subsecretario de Hacienda y vicepresidente del Congreso. Años más tarde algunos medios atribuirán la fundación de la Colonia del Doctor Rubio al ímpetu de la colaboración entre Rubio y el marqués de Mochales (La Hoja Hidrológica, 1920).

Dentro de la Institución Libre de Enseñanza, Rubio ha participado en la creación de la Sociedad para el Estudio del Guadarrama, constituida el 19 de noviembre de 1886 en los locales de la Institución. La lista de socios fundadores concentra una parte considerable de la sustancia científica y cultural del Madrid del momento, como Macpherson, Quiroga, Bolívar, Bernaldo de Quirós, Giner de los Ríos, Cossío, etc., estando Federico Rubio y Galí entre este grupo fundador (Santos Casado, 2010).

Dada su intensa relación con los primeros "guadarramistas", Rubio bien podría haber ollado las faldas de la Sierra de Guadarrama con su amigo Giner de los Ríos. Pero también con su amigo Antonio Machado y los trabajos de campo del colectivo El Folklore Castellano, interesados por la tradición popular 
de los serranos del Guadarrama para ahondar en sus saberes sobre las enfermedades y su curación. Huyendo del discurso positivista más ortodoxo, los folkloristas, y Rubio con ellos, aceptan la incursión del saber popular y la tradición en el campo de la medicina moderna, lo que quizás explique la pervivencia de tratamientos "populares" propios de la hidrología médica en una colonia que quiere ser la avanzadilla médica en la lucha contra la tuberculosis. "Entre la medicina popular y la medicina científica existen, a no dudarlo, como entre el saber vulgar y la ciencia, continuas corrientes de flujo y reflujo. El conocimiento de hoy es base para el conocimiento científico de mañana", escribe Machado a Rubio en una de sus cartas (Perdiguero \& Ballester, 2003).

Por su prestigio y contactos, Federico Rubio y Galí se presenta pues como el avalista y socio perfecto para un proyecto de colonia sanatorial en Guadarrama. Las ideas, sueños y proyectos surgidos en el seno de estas sociedades madrilenas podrían ser claves para entender la materialización de este proyecto, una colonia modelo, una ciudad nueva al pie de la Sierra de Guadarrama, una solución al problema del hacinamiento, un tratamiento para la tuberculosis, la aplicación práctica de los postulados higienistas fuera de las ciudades.

Pero el doctor Rubio, sexagenario cuando se funda la Sociedad de Estudio del Guadarrama, no es un naturalista. Mientras que otros guadarramistas recorren la Sierra de Guadarrama en busca de insectos, plantas y minerales, Rubio vivirá su particular experiencia naturalista a través de la caza. En su libro $\mathrm{La}$ Felicidad Rubio escribe: "Conviene despertar la afición a los placeres honestos: el del campo, el de los viajes, el placer de cultivar flores, el de la caza, etc." (Rubio y Galí, 1894). Eugenio Gutiérrez, amigo personal de Rubio y comisionado por la Academia de Medicina para trazar su primera biografía, señala que Rubio practica la caza desde su retirada de la vida política, en 1875, hasta el mismo año de su muerte:

había procurado un desahogo a su sobrecarga de ácido úrico dedicándose hacía años al deporte cinegético que, a la vez, le prestaba el vigor necesario para el ejercicio profesional y una calma saludable a las profundas perturbaciones morales que determinan actos quirúrgicos (...) (Gutierrez, 1903).

Un mes antes de morir Rubio, la prensa madrileña recordará que el afamado doctor oye hablar de la fama de las aguas medicinales de La Porqueriza durante una jornada de caza en la Sierra de Guadarrama (La Época, 15/07/1901). 
Sin embargo, y pese a estas fuentes, llama poderosamente la atención que los biógrafos y estudiosos de la obra de Rubio no hayan recogido el papel jugado por este médico en la promoción de las aguas de La Porqueriza y en este proyecto de ciudad sanatorial.

Sí se resalta, sin embargo, que entre 1894 y 1902, Rubio se vuelca en la escritura de varios libros (La Felicidad y La Mujer Gaditana) y en la edición de la Revista Ibero-Americana de Ciencias Médicas (Gutierrez, 1903). Según Laín Entralgo, desde 1875 hasta su muerte en 1902, Rubio se dedicará de pleno a "la práctica hospitalaria y privada, su original, tenaz y valioso esfuerzo por elevar el nivel científico y técnico de la medicina española y su labor publicista" (Laín Entralgo, 1977). Otro de sus biógrafos, Alvarez Sierra, señala que "los últimos tiempos de su vida, especialmente los dos últimos años, fueron de relativo descanso, dedicando largas horas a su libro La Mujer Gaditana, su testamento social" (Alvarez Sierra, 1947). Ninguna referencia al papel jugado por Rubio en el proyecto de la colonia que llevará su nombre.

Por lo tanto, no parece que el Doctor Rubio participe activamente en el proyecto ni sea el descubridor del manantial de La Porqueriza. Aunque con posterioridad a su muerte la prensa madrileña atribuirá al médico éste y otros méritos (la fama de las propiedades curativas del manantial, por ejemplo), hay suficientes datos para pensar que estas aguas son ya conocidas antes de que los promotores del proyecto utilicen la figura de Rubio como la mejor propaganda disponible.

Como han señalado algunos estudios sobre la figura de este médico eminente, el enorme bagaje intelectual y prestigio profesional de Rubio reúne las características idóneas para ser elegido como ferviente representante de la clase médica a la cual pertenecía, lo que le convierte en un mito incluso antes de su fallecimiento:

la imagen generada en torno a Federico Rubio no puede calificarse de un hecho excepcional, responde a un modelo elaborado propio de la clase burguesa a la que pertenecía y la cual lo elevó a prototipo modélico, como fiel representante de su clase. El discurso creado sobre su persona revela una maniobra orquestada por la clase médica que necesitada de una reafirmación propia y de reconocimientos sociales y políticos, crea, desarrolla y consume una figura mitificada, en esta ocasión Federico Rubio (Bernal, 2003). 
Visto desde una perspectiva empresarial, el nombre del Doctor Rubio es a finales del siglo XIX el mejor aval científico y la mejor marca publicitaria para un grupo de empresarios madrileños que proyectan construir una ciudad balneario a hora y media de la capital, en la Sierra de Guadarrama, el nuevo espacio de ocio, deporte y salud de la burguesía madrileña.
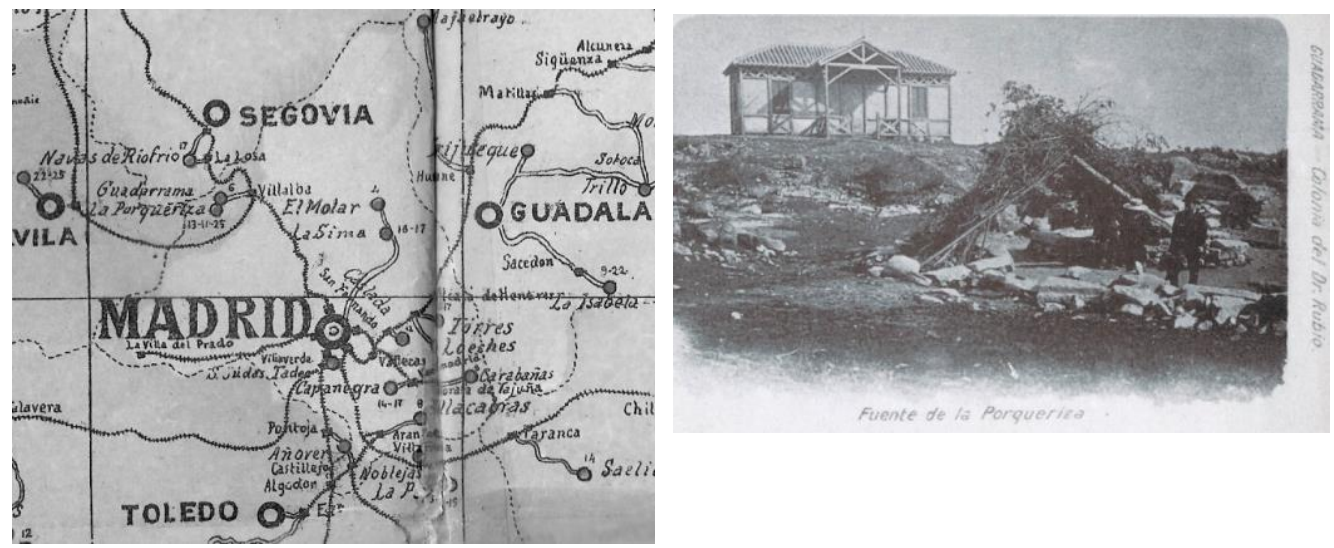

Fig. 1 (izq.) Detalle del Mapa y Consultor Estadístico Hidro-Minero-Medicinal de la Península Ibérica, de 1903, donde aparecen los centros balnearios y manantiales de Guadarrama, La Porqueriza y La Losa (Segovia), y sus conexiones con el trazado ferroviario. Fig. 2: Manantial de La Porqueriza en los primeros años del siglo XX (Fuente: AGM - Archivo Municipal de Guadarrama).

\section{Gestación, auge y decadencia de la Colonia del Doctor Rubio.}

La colonia que lleva por nombre "Doctor Rubio" es un proyecto de ciudad sanatorial balnearia nacida al calor de las corrientes higienistas propias del último tercio del XIX, la evolución del tratamiento de las enfermedades respiratorias, los cambios en la organización sanitaria promovidos por el movimiento regeneracionista o los modelos urbanísticos que buscan resolver los problemas de higiene, hacinamiento y transporte que atenazaban a las ciudades en ese periodo. Y los promotores, además de contar con el apoyo de un gran médico de prestigio, se fijan en la localidad de Guadarrama, que además de sus buenas condiciones de clima y paisaje, tiene a su favor dos elementos determinantes: acceso por ferrocarril hasta la Estación de Villalba y el manantial de aguas minero-medicinales de La Porqueriza (Soto, 2014).

El contexto histórico se complementa con el hecho constatado de que la localidad de Guadarrama es ya antes del cambio de siglo un lugar de cura para los 
enfermos tuberculosos. Según algunas fuentes, en el año 1897 fallece el primer enfermo que procedente de Madrid se hospeda en Guadarrama; y en 1898 el médico titular de Guadarrama, D. Salvador Ortiz, construye la primera villa particular para enfermos tuberculosos (Pinto, 1955).

Los primeros pasos para la construcción de la Colonia del Doctor Rubio se producen en los últimos años del siglo XIX, con la formación de una "Sociedad de Colonización" formada por médicos, políticos, militares y empresarios madrileños (La Época, 15/07/1901).

Entre los fundadores de dicha sociedad, destaquemos tres figuras: el primero, D. José Francos Rodríguez, médico higienista que dirigiría en aquellos años varios medios de prensa escrita y que sería Alcalde de Madrid en el período 1910-1912 y 1917-1918; D. Rafael Sarthou, senador por Valencia, presidente del consejo de administración de la sociedad y futuro propietario de la sociedad durante su decadencia; y el coronel de Ingenieros D. Eligio Souza y Fernández de la Maza, constructor militar con experiencia en África y responsable de la construcción de la colonia y del casino.

El acto de colocación de la primera piedra se celebró en octubre de 1900 (La Correspondencia de España, 25/10/1900) y la inauguración del Hotel, el primer edificio del complejo, el 14 de julio de 1901 (El Liberal, 15/07/1901). En ambos actos estuvieron invitados, además de la prensa, distinguidas personalidades y representantes de la vida política y social madrileña.

La colonia se organizaba en tres vías longitudinales principales cortadas por varias transversales secundarias (CAM, 1999). Una gran calle central bordeada por dos hileras de plátanos y pinos se constituía en la arteria principal de la colonia, a lo largo de la que situaban los hotelitos y el Hotel, de dos plantas (El Heraldo de Madrid, 30/04/1904).

El Casino, inaugurado en 1902, era un edificio aislado, amplio, de elegantes proporciones y de una sola planta, con patio a la andaluza y gran terraza. Construido por el ingeniero militar Sr. Souza, contaba con teatro, servicio de peluquería de baños, salones de baile, de lectura, café, de juegos de tresillo, billar y ping-pong y caballitos (La Época, 22/07/1902).

La colonia disponía de sistema de alcantarillado, vaquería y panadería (La Época, 09/06/1902). También estanco, correos, establecimientos para automóvi- 
les, coches y caballerías. Además del personal al servicio del Hotel y el Casino, la colonia disponía de personal suficiente para todos los otros servicios: administrador, conserje, ordenanzas, encargado del alumbrado, "water-closets", depósitos de aguas, cañerías, etc., encargado de parques y jardines, cocheros, peluquero, sereno, etc. (El Liberal, 23/07/1903).

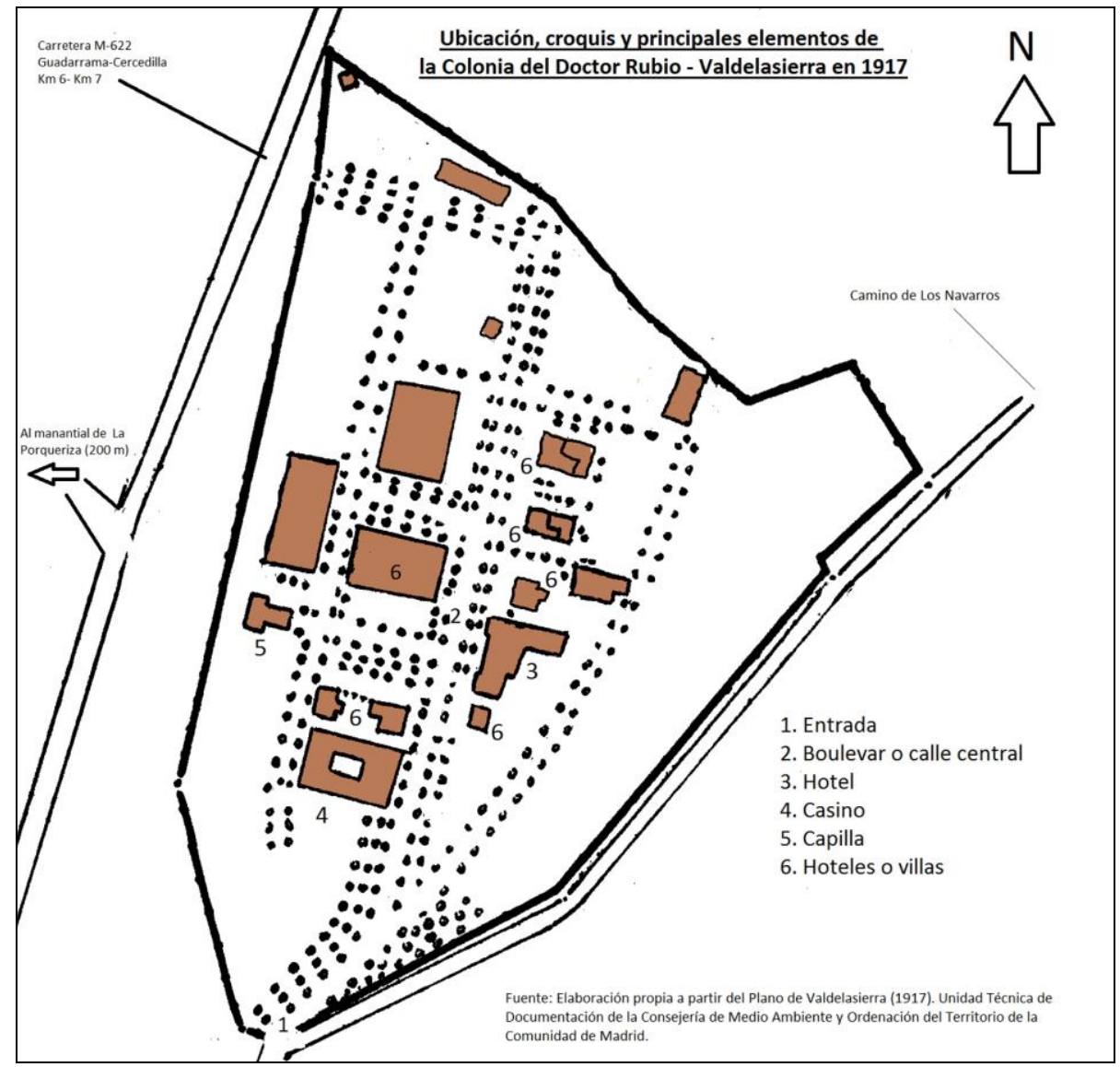

Fig. 3. Reconstrucción de la Colonia del Doctor Rubio y sus elementos principales a partir de un mapa de 1917. (Fuente: elaboración propia, 2015).

Si bien se proyectó la construcción, en edificio separado, de un pabellónsanatorio destinado a personas "enfermas" (La Época, 15/07/1901), donde se situaría el gabinete médico, botiquín y las habitaciones del Médico-Director de la colonia (El Liberal, 23/07/1903), no tenemos constancia de que se llegara a construir. 

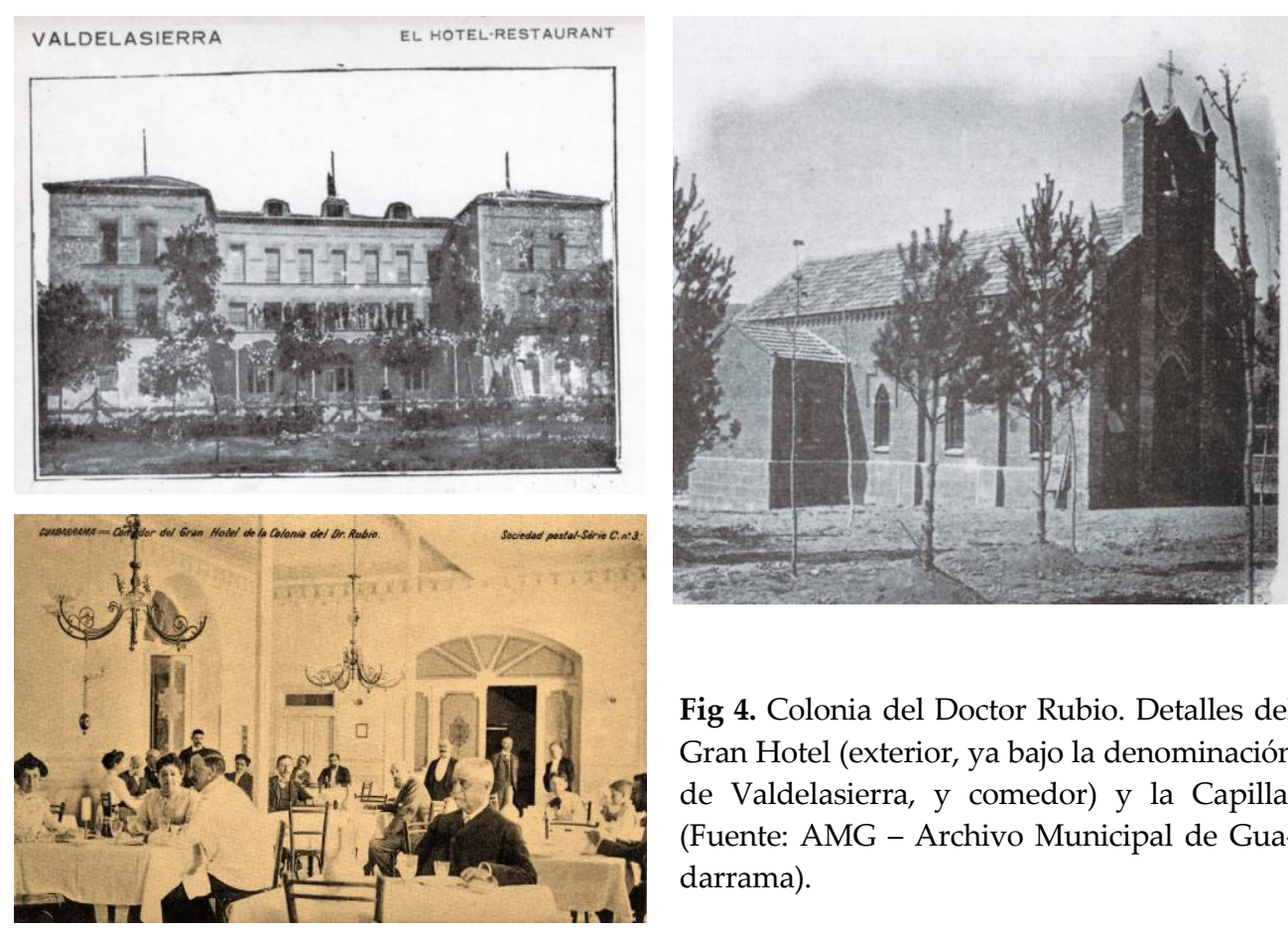

Fig 4. Colonia del Doctor Rubio. Detalles del Gran Hotel (exterior, ya bajo la denominación de Valdelasierra, y comedor) y la Capilla. (Fuente: AMG - Archivo Municipal de Guadarrama).

Entre 1902 y 1912 se produce la época dorada de la Colonia del Doctor Rubio, cuando la "Panticosa de Madrid" es exaltada por la prensa madrileña por su lujo y comodidad y es comparada con los mejores hoteles europeos de Los Alpes (El Liberal, 15/07/1901). En estas primeras décadas del siglo XX, la Colonia del Dr. Rubio será una experiencia del balnearismo propio de la Belle Époque (Soto, 2014). De vuelta a sus redacciones, los periodistas agasajados en Guadarrama enfatizarán el refinamiento y los buenos accesos de este establecimiento:

¿Dónde se encuentra a dos horas de Madrid un lugar fresco, un monde d'élite, hotel espléndido, casino magnífico, con sus caballitos correspondientes; pretexto para lucir toilettes de campo, trajes de alpinista, sombreros adornados con flores silvestres y ocasión de gastar confortable y elegantemente el dinero sin alejarse del centro de los negocios y de la Monarquía? (El Heraldo de Madrid, 05/08/1903).

Entre los años 1912 y 1914 se produce un cambio de nombre, la colonia pasará a llamarse Valdelasierra (La Correspondencia de España, 13/07/1914) y empieza a caer en desuso la costumbre de "tomar las aguas". El médico higienista Baltasar Hernández Briz, autor de las Topografías médicas de la zona, 
señala que el manantial de La Porqueriza está abandonado a comienzos de la década de los años 20 (Hernández Briz, 1927). En 1920 fallece el entonces propietario, D. Rafael Sarthou, dejando en manos de su esposa, la condesa de Medina y Torres, la gestión de la colonia.

Entre 1921 y 1927, Valdelasierra será un hospital militar de evacuación de soldados enfermos de paludismo procedentes de Marruecos, evacuación obligada por el colapso de los hospitales del Norte de África tras el desastre de Annual durante la Guerra de Marruecos, en septiembre de 1921 (Soto, 2014).

Tras su reparación, Valdelasierra vuelve a manos de sus propietarios en 1929, anunciándose nuevamente en la prensa como colonia especializada en "enfermos de las vías respiratorias" (El Siglo Futuro, 02/08/1929). El Sanatorio de Valdelasierra dispone ya de una moderna instalación de Rayos X y todos los tratamientos modernos para la tuberculosis pulmonar: calefacción central, agua caliente, ascensor, dobles ventanas, teléfonos en todas las habitaciones, etc. (Revista Hispano-Lusitana, 1932). En vísperas de la guerra civil, el establecimiento se anuncia emplazado en un lugar con 300 días de sol al año, la atención del Doctor Santiago Cereceda y las modernas cirugías basadas en el colapso pulmonar (La Región, 29/10/1934).

Fig 5. Anuncio del sanatorio de Valdelasierra en la Revista Hispano-Lusitana de 1932.

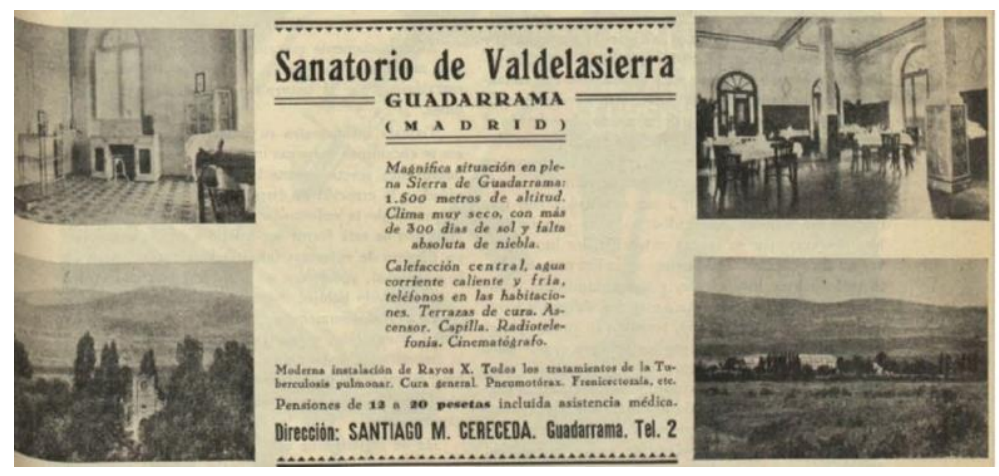

El sanatorio antituberculoso de Valdelasierra será destruido durante la Guerra Civil, debido al intercambio de artillería tras la estabilización del frente en el Puerto del León durante la mayor parte de la contienda. Pese al abandono de las ruinas del establecimiento, la colonia mantendrá los restos de los principales edificios hasta el comienzo de la década de los 70, como se puede observar en las fotografías aéreas de los vuelos 1946 y 1956. 


\section{La Colonia del Doctor Rubio y las utopías del siglo XIX.}

La Colonia del Doctor Rubio constituye la plasmación del ideario del movimiento Higienista, que confiaba en la ciencia, el progreso y las mejoras higiénicas como camino para mejorar la salud y la existencia humana; que valoraba la importancia de la cultura popular y la función sanadora de la naturaleza.

El Doctor Rubio, junto con otros médicos, políticos y militares que forman la sociedad promotora del proyecto, se convierten así en la avanzadilla de la cura sanatorial en altura en el Guadarrama. Como ya hicieran sus homólogos los tisiólogos europeos, los higienistas se convierten en teóricos de la arquitectura y del urbanismo moderno en el medio rural.

\subsection{Hygeia, la ciudad higiénica, la "ciudad ideal".}

En 1876, el médico higienista inglés Benjamin Ward Richardson publica Hygeia: Una Ciudad de la Salud (Hygeia: A City of Health)1 ${ }^{1}$, una formulación de un modelo de ciudad salubre, capaz de combatir las enfermedades de su tiempo. La utopía de Richardson sirvió de inspiración para la creación de las primeras colonias tuberculosas inglesas. Muchas de las innovadoras soluciones arquitectónicas y urbanísticas propuestas por los arquitectos del Movimiento Moderno que a mediados del siglo XX comenzaron a materializarse, ya habían sido plasmadas en Hygeia (Ruiloba Quecedo, 2011).

Hygeia, donde no se permite el consumo de alcohol ni tabaco, es una ciudad perfectamente equipada para la cultura, el descanso y la salud, y contaba con bibliotecas, gimnasios, piscinas, baños turcos, etc. Las viviendas a partir de dos pisos tenían ascensor y donde el dormitorio era una de las estancias más cuidadas de la casa. Se buscaba el contacto con la naturaleza, por lo que las viviendas disponían de "cubiertas jardín" y se rodeaban de vegetación, al igual que los edificios públicos, situados en las áreas verdes de la ciudad (Ruiloba Quecedo, 2011).

\footnotetext{
${ }^{1}$ Hygeia o Higía ( $\Upsilon$ $\gamma \varepsilon$ cía/Hygieía o $\Upsilon \gamma \varepsilon$ cía/Hygeía) era hija de Asclepio y hermana de Yaso y Panacea. En el panteón griego, Hygeia era la diosa de la curación, la limpieza y la sanidad, mientras que su padre estaba relacionado con la medicina. Hygeia significa "salud", y su evolución ha dado lugar a la palabra "higiene", siendo su equivalente en la mitología romana "Salus".
} 
Estos también eran los principios en la Colonia del Doctor Rubio. La liturgia de tomar las aguas, pasear y reposar formaban parte de un modo de vida higienista que ya se había extendido en los sanatorios antituberculosos de Centroeuropa en décadas anteriores (Soto, 2014). Incluso el servicio de peluquería del casino esterilizaba el material utilizado, algo impensable en el Madrid de la época. "Como se ve, las prescripciones higiénicas del doctor Rubio se emplean rigurosamente" (La Época, 22/07/1902). Los comentarios e ironías de los detractores del proyecto sirven también para ilustrar las nuevas costumbres de este proyecto higienista:

en la Colonia se ven por todos lados letreros impidiendo coger flores, llevar perros, escupir en el suelo, ir de prisa, ir despacio, etc.; allí no se consiente más que jugar a los caballitos en el casino y tomar un agua desagradable a legua y media de distancia del Establecimiento o Gran Hotel. Yo no sé cómo los enfermos del pecho no sienten mayor opresión entre aquella serie de restricciones a la libertad (Nuevo Mundo, 31/08/1905).

Hygeia pone en evidencia que fueron los médicos los que mostraron el camino a los arquitectos y urbanistas del siglo XX a la hora de mejorar la salud a través de la arquitectura y cómo, atendiendo a las necesidades de los enfermos, podrían llegar a concebirse ciudades saludables (Ruiloba Quecedo, 2011).

\subsection{La Ciudad Lineal de Arturo Soria.}

La Ciudad Lineal es concebida por Arturo Soria y Mata en 1882 y la primera piedra es colocada en 1894. Federico Rubio es coetáneo de Soria y del arquitecto Belmás, y su colonia sanitaria en Guadarrama se mirará en el espejo de la ciudad que ambos construyen con muy pocos años de anticipación.

La Ciudad Lineal y la Colonia del Doctor Rubio compartirán el carácter racional de la trama urbana, con una calle ancha y arbolada como eje central, servicios de correos, agua y luz eléctrica, e instalaciones y centros comunitarios aptos para el desarrollo de la vida social. Una ciudad "autosuficiente y autónoma". Otros elementos comunes a ambos proyectos son las calles con doble hilera de árboles; o las novedades de diseño arquitectónico, como viviendas unifamiliares con parcela para huerta o jardín.

Como otros higienistas, Soria quiere "desterrar el vicio moral y físico de la ciudad desordenada, hacer florecer una vida más higiénica y armoniosa en to- 
dos los sentidos". Soria defiende que la salvaguardia del individuo se lograba a través del contacto con el paisaje natural unido a la vida social (Bonet, 2001). Para ello, el arquitecto Manuel Belmás introdujo nuevas técnicas y materiales. A nivel tipológico, planteó como ideal la vivienda unifamiliar, influencia del mundo anglosajón, tratando de buscar una perfecta funcionalidad, tanto de plantas como en el empleo de los nuevos materiales (Barreiros Pereira, 1992). Vistas las similitudes en la tipología de las viviendas de la Ciudad Lineal y la Colonia del Doctor Rubio, parece razonable pensar que ambos proyectos son fruto del mismo ideario.

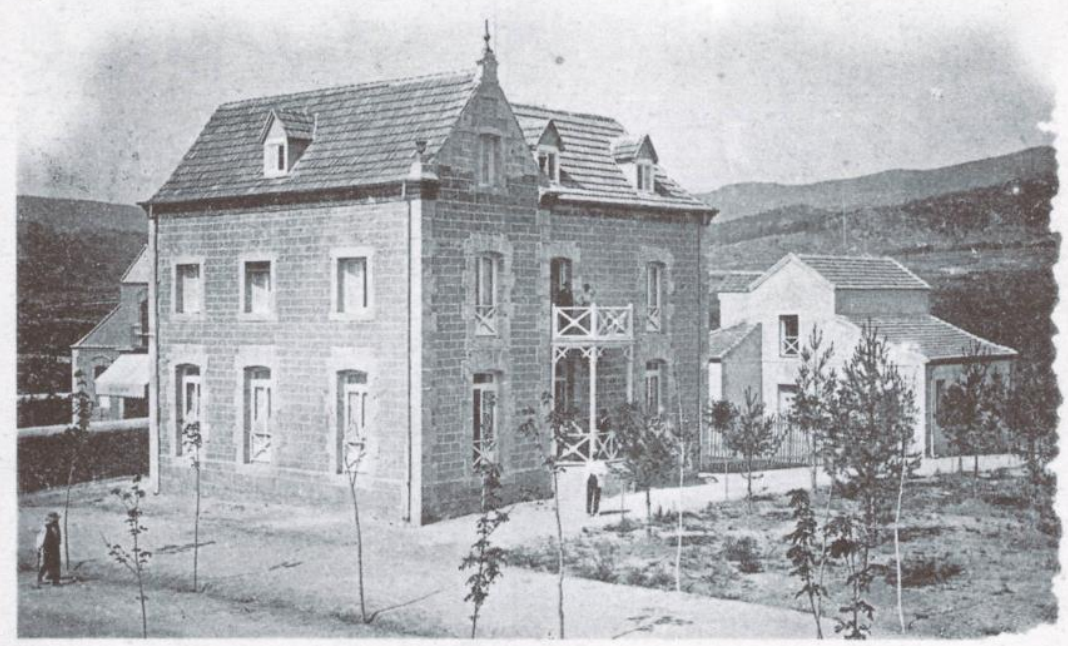

Fig 6. Vivienda de dos plantas de la Colonia del Doctor Rubio. (Fuente: AMG - Archivo Municipal de Guadarrama).

Cuando Belmás y Soria proponen el aislamiento de la casa en el jardín, la limitación de alturas en las construcciones, la distancia que éstas deberán observar respecto a la calle, etc., estamos viendo, según Navascués, al representante de un movimiento que pretende reformar la sociedad a través de un marco físico adecuado (Navascués, 1979). Arturo Soria, dice Navascués, es un ferviente lector de Julio Verne y sueña su Ciudad Lineal tras la lectura de la nove- 
la Los quinientos millones de la Bégum, publicada en 1879, en la que Verne propone una ciudad modélica y entre cuyos postulados iniciales se encuentran: primero, cada casa estará aislada en una porción de terreno plantado de árboles, de hierba y de flores. Será habitada por una sola familia; segundo, ninguna casa tendrá más de dos pisos. El aire y la luz no deben ser acaparados por unos con perjuicio para los demás; tercero, todas las casas tendrán la fachada a diez metros de la calle, de la que estarán separadas por una verja de conveniente altura. La distancia que quede entre la verja y la fachada estará destinada a jardín, etc. El propio Julio Verne reconoce que estas prescripciones las había tomado del texto de Richardson (Navascués, 1979). Y si Julio Verne bebe de Richardson, Soria ha leído a Verne, podemos aventurar que Rubio mira de reojo a sus amigos Soria y Belmás, y sueña también con una Hygeia en Guadarrama, similar a la ciudad que Soria está construyendo Madrid.

Para las viviendas de la Ciudad Lineal, Soria y su colaborador Belmás establecen unas bases tipológicas estandarizadas o catálogos de modelos de casa. Propia del fin de siglo, la arquitectura ecléctica combina elementos de diferentes estilos y épocas. En la Colonia del Doctor Rubio, las casas de campo o villas inauguran la "arquitectura del veraneo" en la Sierra de Guadarrama, arquitectura que podemos conocer a través de fotografías y postales antiguas que reproducen algunos de los modelos de hoteles levantados por Belmás en la Ciudad Lineal. En los primeros años, las primeras viviendas de la colonia tienen planta en forma de L y sin adornos, para posteriormente diversificarse la tipología con recercado de vanos y fajas decorativas en sus fachadas (carpintería colgada de madera o "guardamalletas"), elementos claramente tomados del repertorio arquitectónico del chalet suizo.

Fig 7. Chalet Suizo de la Colonia del Doctor Rubio. (Fuente: AMG - Archivo Municipal de Guadarrama).

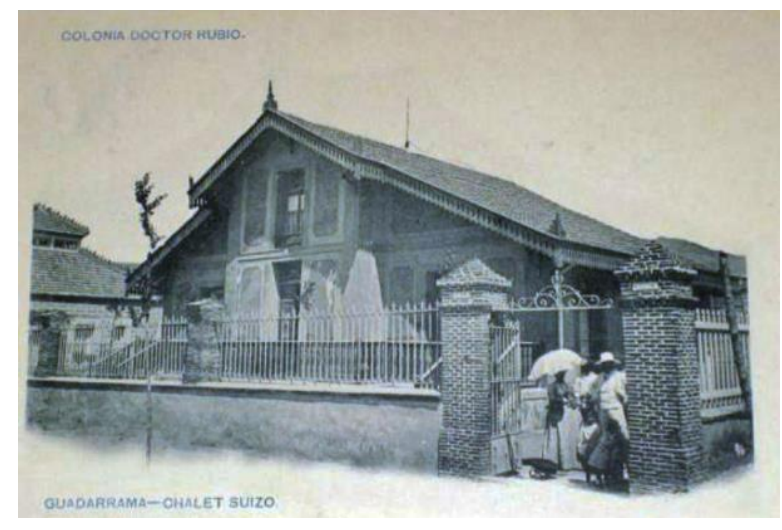


Ecléctica y cosmopolita, la Colonia del Doctor Rubio es el escenario perfecto para la nueva costumbre del veraneo, escuela de pautas de comportamiento social y escaparate de las modas, donde la función sanitaria de la Colonia irá perdiendo protagonismo a favor de las excursiones, nuevos deportes, los juegos en el casino, las tertulias y, en definitiva, las múltiples y nuevas expresiones de ocio que permiten la vida alegre y animada característica de la Belle Èpoque.

En el mes de julio de 1902, cuando el termómetro en Madrid marca 42 grados a la sombra y la atmósfera urbana se llena de los vapores de las cloacas y el asfalto reblandecido, la revista La Ciudad Lineal proclama “Qué vida más heroica la de los que no tenemos posibles para ir a La Porqueriza" (20/07/1902).

\subsection{La ciudad balnearia, entre la salud y el veraneo.}

El éxito inicial de la Colonia del Doctor Rubio se aprovechará del auge de la "ciudad de las aguas" que surge en el siglo XIX en torno a una fuente mineromedicinal o una ciudad marítima. Al año de inaugurarse la Colonia, se inaugura en Guadarrama el Hotel-Balneario de La Alameda, único balneario sensu stricto según los manuales de Hidrología Médica, permaneciendo operativo hasta 1928, año en el que es transformado en un Preventorio Infantil para la lucha anti-tuberculosa (Soto, 2014). En ambos casos, estas experiencias empresariales pueden interpretarse como un intento de imitar a escasos kilómetros de la Corte los grandes complejos hidrotermales de interior que se habían puesto de moda entre la aristocracia en el último tercio del siglo XIX: las termas de pasado romano (Alange, Baños de Molgas, Lugo, Fitero, Panticosa, Caldas de Montboi, Sierra Alhamilla,...), árabe (Alhama de Aragón, La Garriga, Granada y Murcia, Lanjarón) o aquellas bajo la protección de un monasterio (Segura de Aragón, Fontcalda, etc.).

Con una colonia higienista para enfermos de pecho y un hotel-balneario para enfermos del estómago, la localidad de Guadarrama compitió durante unos años en la liga de establecimientos donde pasar el verano, en un momento histórico que constituyó la segunda edad de oro del balnearismo en España.

La prueba de que la Colonia del Doctor Rubio, como la ciudad de las aguas, tiene una fuerte asociación temprana con el veraneo, es que en la localidad de Guadarrama, antes del cambio de siglo ya existía una importante colonia de veraneantes, colonia que junto a los veraneantes de El Escorial, Cercedilla, Vi- 
llalba y otros pueblos acudían a tomar las aguas de La Porqueriza (El Heraldo de Madrid, 15/08/1899). En 1900, la prensa ya se refiere a La Porqueriza como un manantial de aguas nitrogenadas, conocido en "media España" (Heraldo de la Industria, 4/08/1900).

Tomar las aguas, veranear fuera de Madrid, los juegos sociales en torno a las casas de baños, son los nuevos usos sociales de la burguesía (Sazatornil, 2007). En referencia a los distintos movimientos utópicos, Leboreiro señala que la "ciudad de las aguas" recoge el concepto de la regeneración, de la recuperación del santuario antiguo convertido en un mundo de nostalgia. Así, la ciudad de las aguas es en sentido etimológico, una utopía (Leboreiro, 1991).

El veraneo en la Colonia del Dr. Rubio es un intento de imitar a la aristocracia que visita Biarritz, Mondaríz o San Sebastián (Soto, 2014), con "gente fina, distinguida, elegante, culta" y "mujeres guapísimas, correctos caballeros" (El Gráfico, 10/08/1904). La estancia en la Colonia estaba salpicada de momentos llenos de placidez y candor que incluían misa diaria (La Época, 22/07/1902), paseos a tomar las aguas a La Porqueriza, tertulias, juegos de mesa o lectura de la prensa.

$\mathrm{Al}$ aire libre, en rústicas mesitas, se toma el desayuno. (...) Ancianas respetables, de noble continente, contemplaban, dichosas, el animado jugueteo de los niños. A su lado, sentadas, bellas señoritas tejían con sus rosados dedos primorosas labores, mientras los hombres serios jugaban al ajedrez, leían la prensa o hablaban de política sosegadamente, y acaso algún pollo elegante y correcto miraba de soslayo a una linda muchacha. (...) Por la tarde, en coche, a pie, en burro, se verifican excursiones a los preciosos alrededores y acuden de nuevo los agüistas al manantial ya famoso (El Gráfico, 10/08/1904).

Estos comentarios de la prensa avalan la afirmación de Leboreiro de que el ritual termal es sólo un elemento más. La ciudad de las aguas es un lugar de encuentro en el que la nobleza, políticos y artistas avalan el nuevo espacio y ello se hará constar en las reseñas periodísticas, fenómeno ligado a la apropiación por la burguesía de un espacio hasta entonces reservado a la nobleza (Leboreiro, 1991).

La misma existencia de un casino en la Colonia del Dr. Rubio revela, según los estudiosos del fenómeno, el paradigma de la frivolidad que en alguna manera es el encanto principal de la arquitectura "balnearia", más contenida en el 
establecimiento termal tradicional: centro de medicina, reposo, honesta diversión y cultura. Como en otros centros balnearios europeos, la Colonia de Rubio aparece como una ciudad planificada, donde la naturaleza tiene una importancia capital, "donde el paciente deja de serlo para ser usuario" (Leboreiro, 1991).

\subsection{Los sanatorios antituberculosos.}

La implantación del tratamiento de la tuberculosis basada en la cura de reposo en sanatorios situados en las montañas se produciría durante todo el siglo XIX, y de manera simultánea, cuando médicos alemanes y británicos constatan los beneficios de la altura, el sol y el aire sobre los enfermos tuberculosos.

Ya hemos expuesto que la Colonia del Doctor Rubio es, en lo arquitectónico, una pequeña Ciudad Lineal en la periferia de Madrid; $y$, en lo funcional, una estación veraniega, un balneario. Pero no puede definirse todavía como un "sanatorio antituberculoso" ya que su fundación se produce con una década de antelación a las primeras iniciativas que tratan de reproducir en la Sierra de Guadarrama el modelo de sanatorio antituberculoso que se ha generalizado en las estaciones alpinas de Suiza, en las montañas de Alemania y en los cottages ingleses y americanos.

La Colonia del Doctor Rubio nunca será anunciada o publicitada como "sanatorio antituberculoso" a pesar de que es contemporánea de la construcción de los primeros centros especializados en España: en 1897 se ha inaugurado el Sanatorio Antituberculoso de Busot (Alicante), destinado a clases acomodadas; y en 1899 el de Porta-Coeli (Valencia), para clases populares. Y ya hemos comentando que antes del cambio de siglo empiezan a llegar los primeros enfermos de tuberculosis a la localidad de Guadarrama, buscando la cura en altura que se ha implantado en Europa.

Gestada bajo otras premisas, la colonia de Guadarrama muy pronto sufrió el impacto de la generalización de la cura sanatorial en altura. Al año de su fundación, en 1902, el periódico La Correspondencia de España informa de la existencia de un proyecto adjunto a la colonia:

un verdadero sanatorio modelo para tuberculosos, sanatorio que, de acuerdo con el doctor Verdes Montenegro y bajo su dirección, se ha de construir próximo a la colonia y en el sitio que se considere más conveniente (La Correspondencia de España, 25/08/1902), 
Dos años después, en 1904, la prensa seguirá anunciando la futura construcción de un pabellón sanitario análogo a los sanatorios antituberculosos de Feydensur-Leysin y Davos-Platz en Suiza

en los que la cura de los enfermos del aparato respiratorio por el tratamiento higiénico o dietético y el tratamiento climatológico gana camino cada día con pruebas evidentes de su eficacia (La Época, 12/06/1904).

Pero en un balneario la palabra tuberculosis es todavía un tabú. Los enfermos lo son de las "vías respiratorias", y cuando se proyecta el pabellón médico se diseña como pabellón adjunto, aislado del resto de viviendas y los equipamientos. Por las serias contradicciones de dicha propuesta, nunca se llegó a construir.

Por esta razón nos inclinamos a no considerar la Colonia del Doctor Rubio un "sanatorio antituberculoso", pese a que todos los médicos de la Colonia del Doctor Rubio serán sucesivamente reputados doctores de la lucha antituberculosa en España. Tras la muerte del Doctor Rubio en 1902, le sustituirá su discípulo el doctor José Verdes Montenegro (La Correspondencia de España, 25/08/1902), médico fundador de la lucha antituberculosa en España, fundador de varios dispensarios y sanatorios antituberculosos y Director General de Sanidad durante la II República. En 1904 le relevará en el cargo el doctor Eduardo Méndez del Caño, ayudante del doctor Silariani en el Hospital de la Princesa (La Época, 12/06/1904).

En España, y en épocas tan tempranas como 1901, la Colonia del Doctor Rubio sólo puede ser entendida como la vanguardia de la lucha antituberculosa fuera de las ciudades, como un establecimiento a medio camino entre el balneario y el sanatorio, experimento que sucumbirá ante la generalización de la cura de reposo en altura. Incluso en la segunda década del siglo, ya bajo el nombre de Valdelasierra, la colonia no recibirá el calificativo de "sanatorio antituberculoso", pese a que la dirección facultativa estará a cargo del doctor Julio Sousa, alumno de Verdes Montenegro durante su estancia en el Dispensario Antituberculoso de María Cristina (primer dispensario en España de carácter tuberculoso) y Secretario de la Liga Popular contra la tuberculosis (Mondaríz, 20/10/1920).

Los intentos de implantar la cura sanatorial en altura en las faldas de Guadarrama se harán realidad una década después de colocada la primera piedra en la colonia, hacia 1912, cuando el Doctor Gereda, médico higienista y 
miembro de la Liga Antituberculosa, publica su primer proyecto del Real Sanatorio de Guadarrama (Vías, 2011), que será inaugurado en 1917. Le seguirán el Sanatorio de la Fuenfría (Cercedilla), en 1921, y el sanatorio del Doctor Lago, en La Tablada (Guadarrama), en 1924. La costumbre de tomar las aguas dará paso a la cura sanatorial en altura, con buena alimentación y exposición al sol y el aire.

Sólo a partir de 1929, con el nombre ya consolidado de Valdelasierra, y con las viviendas convertidas en centros de reposo para enfermos tísicos, el establecimiento se anunciará claramente como un centro antituberculoso, estando a cargo del establecimiento el doctor Santiago Martínez Cereceda, otro afamado médico de la lucha antituberculosa en este periodo.

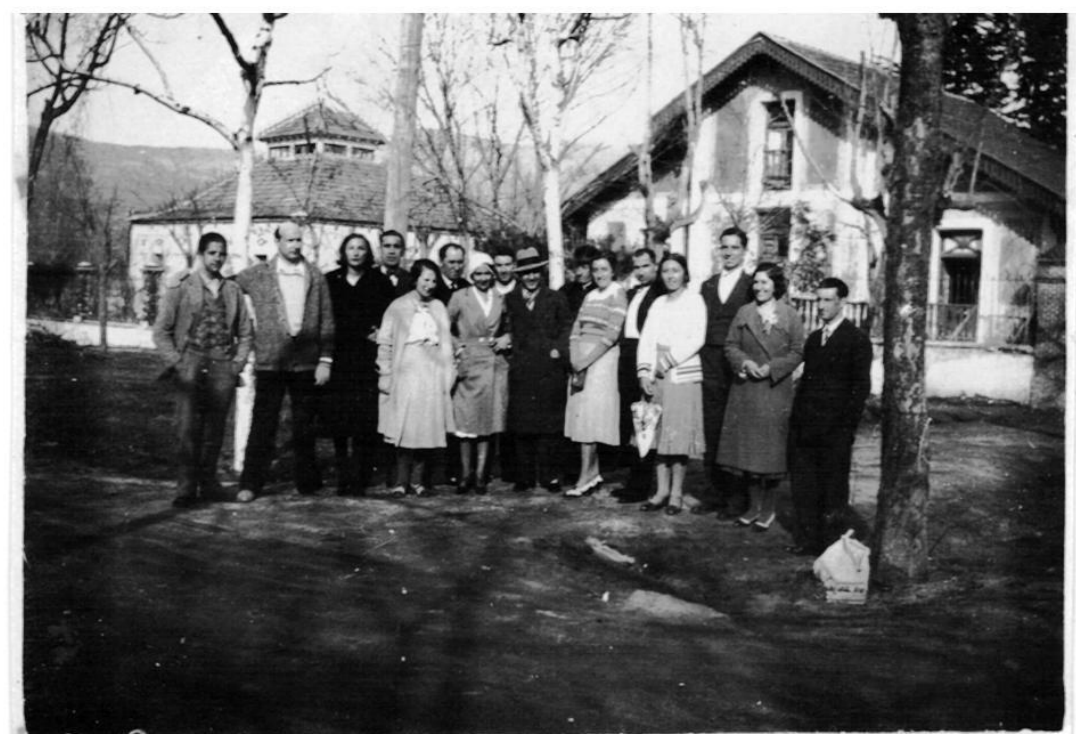

Fig 8. Grupo de enfermos con el Dr. Cereceda en Valdelasierra, 1931. (Fuente: Archivo personal Fernando Díaz Espada).

\section{Conclusiones.}

En un momento en el que la insalubridad y la tuberculosis afectaban de manera importante a la población de Madrid, la localidad de Guadarrama (Comunidad de Madrid, España), situada a los pies del Puerto del León, se constituyó en un centro balneario y una villa de reposo para los sectores más acomodados de esta urbe. 
La Colonia del Doctor Rubio es la materialización de las ideas del Movimiento Higienista, como triunfo de la higiene sobre los hábitos sociales viciados, hasta el punto de convertir a los médicos en ideólogos de la arquitectura y el urbanismo. Un nuevo modelo de ciudad en contacto con la naturaleza, una nueva forma de vivir para una sociedad nueva. Una utopía.

Esta utopía toma el nombre de un médico elevado a la categoría de mito por su misma clase social, el doctor Federico Rubio y Galí: un hombre que acumula experiencia médica y revoluciones políticas; que ha bebido de las corrientes europeas y americanas en sus estancias y viajes en Inglaterra, Francia o Estados Unidos; que ha sido pionero en varias especialidades quirúrgicas y fundador de institutos de enseñanza operatoria; que comparte inquietudes con todos los movimientos e instituciones progresistas del Madrid de su época; que está bien relacionado con las élites gobernantes y con la Realeza. El Doctor Rubio es la mejor marca para un proyecto que es el resumen de todo lo discutido y anhelado por Higienistas, Regeneracionistas e Institucionalistas.

La elección de la localidad de Guadarrama y su manantial de La Porqueriza descarta otras fuentes de aguas minero-medicinales madrileñas de mayor tradición popular, como las de Moralzarzal, Sumas-Aguas o El Molar. La localidad de Guadarrama cuenta con una oferta única: clima de montaña, ubicación perfecta al pie de la Sierra de Guadarrama y buenas comunicaciones. Y esta temprana especialización en la búsqueda de la salud en Guadarrama dejará una honda huella en esta localidad madrileña, siendo a partir de este momento un lugar señalado en el mapa nacional de la lucha antituberculosa.

La Colonia del Doctor Rubio será concebida como una ciudad de cura y una estación veraniega al mismo tiempo. Formará parte del ideario que se ha ido configurando durante la segunda mitad del siglo anterior para denunciar los problemas de la nueva ciudad industrial y la necesidad de una vuelta a la naturaleza. Rubio, como Arturo Soria, como los constructores de balnearios, creen que la salvaguardia del individuo se lograba a través del contacto con el paisaje natural y la vida social.

Los promotores de la Colonia del Dr. Rubio aprovechan las condiciones paisajísticas que rodean el manantial de La Porqueriza, en Guadarrama, para configurar una "ciudad-jardín" con los equipamientos necesarios para el disfrute y 
el glamour, lujo necesario para atraer la clientela y competir con centros balnearios de mayor renombre. En este sentido, la colonia es, sin llegar a ser un sanatorio sensu strictu, precursora de la cura sanatorial en altura que se implantará masivamente en el Alto Guadarrama en las décadas siguientes.

Desde varios puntos de vista, la Colonia del Doctor Rubio representa un modelo urbanístico vanguardista que merece ser rescatado: por plasmar las utopías del movimiento higienista del XIX; por su contemporaneidad y similitudes con la Ciudad Lineal de Arturo Soria; por su intento de generar una industria balnearia en la provincia de Madrid; y por ser la avanzadilla de la lucha antituberculosa en la Sierra de Guadarrama. Y todo ello en un momento en el que la Sierra de Guadarrama es exaltada como lugar de salud y de ocio, convirtiéndose en un hervidero de excursionistas, científicos, montañeros, veraneantes y enfermos. Momento que marca también el comienzo de la ocupación y la transformación profunda de este territorio que se producirá durante la segunda mitad del siglo XX.

La ciudad higiénica, la ciudad saludable o la ciudad de las aguas, cualquiera que sea la aproximación elegida para definir la Colonia del Doctor Rubio, pierde su razón de ser durante la segunda década del siglo XX. La eficacia de los tratamientos propios de la Hidrología médica será fuertemente contestada, y el manantial de aguas minero-medicinales de La Porqueriza será abandonado.

El modelo sanatorial que empezará a desarrollarse en el Alto Guadarrama a finales de la segunda década del siglo XX sustituirá al balnearismo en la identificación entre salud y naturaleza. Los higienistas e institucionalistas han construido el imaginario de la Sierra de Guadarrama como "sanatorio natural" y el testigo es recogido por los médicos de la lucha antituberculosa.

Ya bajo el nombre de Valdelasierra, la vieja colonia del Doctor Rubio se sumará en 1929 al grupo de sanatorios y preventorios para enfermos tuberculosos que llenaran las faldas de la Sierra de Guadarrama en los años previos a la guerra civil española. 


\section{Bibliografía.}

Álvarez Sierra, J. (1947): El Dr. D. Federico Rubio. Vida y obra de un cirujano genial. Editorial Nacional, Madrid.

BARreiros PereIRA, P. (1992): Casas Baratas. La vivienda social en Madrid 19001939, COAM, Madrid.

BÁGUenA CERVELleRA, Ma J. (1992): La Tuberculosis y su Historia. Colección Histórica de Ciencias de la Salud no . Fundación Uriach 1838. Barcelona.

BERNAL, Encarnación (2003). “La construcción social de un mito: el caso de Federico Rubio. En Medicina y sociedad en la España de la segunda mitad del siglo XIX: una aproximación a la obra de Federico Rubio y Galí, (18271902)". En CARRILLO MARTOS (2003).

BONET CORREA, Antonio (1991): "Paisaje Urbano, Ciudad Lineal y Masonería". En Ciudad y Territorio, 89, pp.247-269.

CARriLlo MARTOS, J. L. (Ed.) (2003): Medicina, Estado y Sociedad en la España de la segunda mitad del siglo XIX: Una aproximación a la obra de Federico Rubio y Galí (1827-1902). Ayuntamiento de El Puerto de Santa María y Asociación para la Formación e Investigación y Asistencia Médica de Andalucía “Federico Rubio", El Puerto de Santa María.

COMUNidAd De MADRID (1999). Arquitectura y Desarrollo Urbano. Comunidad de Madrid (Zona Oeste). Tomo VII. Dirección General de Arquitectura y Vivienda de la Consejería de Obras Públicas, Urbanismo y Transportes, Fundación Caja Madrid y Colegio Oficial de Arquitectos de Madrid. Madrid.

GutierReZ, E. (1903): “Biografía del Excmo e Ilmo Sr. D. Federico Rubio y Galí". Anales de la Real Academia de Medicina, 2-3, pp 103- 151.

GÓMEZ FERNÁNDEZ, J. (2003): "Mis maestros y mi educación: la etapa portuense de Don Federico Rubio y Gali”. En CARRILLO MARTOS (2003).

HeRnÁNDEZ BRIZ, B. (1927): Geografía o Topografía médica del Partido Municipal de San Lorenzo. Imprenta de la Ciudad Lineal, Madrid.

HERRERA RODRÍGUEZ, F. (2002): “Un acercamiento a la obra de Federico Rubio y Galí (1827-1902)". En Revista de Historia de El Puerto, 29, pp. 63-88. 
HuERTAS, R. (2002). “Vivir y morir en Madrid: la vivienda como factor determinante del estado de salud de la población madrileña (1874-1923)". En Asclepio Vol. LIV-2-, pp 253-276.

Laín EnTRAlGO, P. (1977): "Prólogo" de Rubio Y Galí, Federico. Mis maestros y mi educación: un hombre ante sí mismo. Editorial Tebas, Madrid.

Leboreiro AmARO, M‥ A. (1991): “Balneario-Ciudad de las Aguas. Su presencia en España”. En Ciudad y Territorio, 89, Verano 3/1991, pp. 213-229.

López HurTADO, A. y SOTO CABA, M.A. (2013): “El establecimiento de aguas minero-medicinales de La Fe en el Portillo de La Mina (Moralzarzal, Comunidad de Madrid)". En De Re Metallica, 20, pp. 37-45.

MANZANEQUE, M. (1882): “Aguas Minerales más convenientes en el tratamiento de la tuberculosis" (Memoria leída en el Congreso Médico de Sevilla del año 1882). En Anales de la Real Academia de Medicina, 1881-1882, pp. 469-477.

MARSET CAMPOS, P., SÁEz GÓmEZ J.M. (2003): “Medicina, Estado y Sociedad en la España de la Segunda mitad del siglo XIX". En CARRILlO MARTOS (2003).

MARTíNEZ GALÁN, I. (1997): Balnearios y Manantiales de aguas minero-medicinales de la Comunidad Autónoma de Madrid. Ediciones de la UCLM, Madrid.

NAVASCUÉS PAlACIO, P. (1979): La Ciudad Lineal. Espasa-Calpe. Madrid.

PALAO IBAÑEZ, Ma . C. (2010): “Una perspectiva social de la tuberculosis en España, 1900-1939". En Scientific Meeting Health and towns in Spain, 1880-1940. Barcelona.

Perdiguero Gil, E. y BALLESTER AÑón, R. (2003): “Federico Rubio y el Folklore Médico". En CARrillo MARTOS (2003).

PINTO, P. (1995): Información Urbanística de Guadarrama. Memoria. Unidad Técnica de Documentación de la Consejería de Medio Ambiente y Ordenación del Territorio de la Comunidad de Madrid. Inédito.

RuBio Y GALí, F. (1977): Mis maestros y mi educación: un hombre ante sí mismo. Prólogo de Pedro Laín Entralgo. Editorial Tebas, Madrid.

RuBIO Y GALÍ, F. (1894): La Felicidad: primeros ensayos de Patología y Terapéutica Social. Imprenta de Enrique Teodoro, Madrid.

RuILOBA QuECEDO, C. (2011). La Ciudad de la salud: los sanatorios antituberculosos. En Ciudades 14 (1): 213-232. 
SAntos CASAdo (2010): Naturaleza Patria, Madrid: Marcial Pons Historia, Madird, pp. 155-156.

SAZATORNIL RUIZ, L. (2008): “Arquitectura, salud y ocio: la edad de oro de los balnearios". En Actas de los XIX Cursos Monográficos sobre el Patrimonio Histórico (Reinosa, 2008), José Manuel IGLESIAS GIL (ED.).

SAZATORNIL RUIZ, L. (2007): “Los orígenes del veraneo en España: playas urbanas, ciudades balneario y arquitectura elegante". Actas del IV Curso Internacional de Relaciones Puerto-Ciudad (Santander, 2007).

Soto CABA, M.A. (2014): “Agua, salud y sociedad en la Sierra de Guadarrama, 1890-1936. El manantial de aguas minero-medicinales de La Porqueriza y el balnearismo en Guadarrama (Comunidad de Madrid)". En Espacio, Tiempo y Forma. Serie VI, Nueva época Geografía no 4 y5, 2011-2012. Universidad Nacional de Educación a Distancia, Madrid.

TAboAda, M. y CARretero, M. (1900): Resumen Estadístico Oficial de las Aguas Minerales de España correspondiente a las temporadas 1890- 1897. Imprenta de Ricardo Rojas, Madrid.

UNIDAD TÉCNICA DE DOCUMENTACiÓN de la Consejería de Medio Ambiente y Ordenación del Territorio de la Comunidad de Madrid. Plano de Población de Valdelasierra (Colonia). Término Municipal de Guadarrama. 1917.

VÍAs, Julio (2011): Memorias del Guadarrama. Historia del descubrimiento de unas montañas. Ediciones La Librería. Madrid.

\section{Hemeroteca}

HERALDO DE LA INDUSTRIA, 04/08/1900

EL GRÁFICO: 10/08/1904, pp 5-7.

EL HERALDO DE MADRID: 15/08/1899; 05/08/1903; 30/04/1904.

EL IMPARCIAL: 03/11/1890; 09/08/1899.

EL LIBERAL: 15/07/1901; 23/07/1903.

EL SIGLO FUTURO: 02/08/1929.

LA CIUDAD LINEAL, 20/07/1902. 
LA CORRESPONDENCIA DE ESPAÑA: 25/10/1900; 25/08/1902; 13/07/1914.

LA ÉPOCA: 02/06/1889; 15/07/1901; 09/06/1902; 22/07/1902; 12/06/1904.

LA HOJA HIDROGEOLÓGICA nº 3, 20/10/1920.

LA REGIÓN, 29/10/1934.

MONDARÍZ, 20/10/1920.

NUEVO MUNDO, 31/08/1904.

REVISTA HISPANO-LUSITANA no 2, noviembre de 1932, pp 89-96. 